\title{
CMIP5 Model Intercomparison of Freshwater Budget and Circulation in the North Atlantic
}

\author{
JULIE DESHAYES \\ ICEMASA, University of Cape Town, Cape Town, South Africa, and Laboratoire de Physique des Océans, CNRS IRD IFREMER \\ UBO, Plouzané, France, and Woods Hole Oceanographic Institution, Woods Hole, Massachusetts \\ RUTH CURRY \\ Woods Hole Oceanographic Institution, Woods Hole, Massachusetts \\ RYM MSADEK \\ Geophysical Fluid Dynamics Laboratory, National Oceanic and Atmospheric Administration, Princeton, New Jersey
}

(Manuscript received 27 September 2012, in final form 13 January 2014)

\begin{abstract}
The subpolar North Atlantic is a center of variability of ocean properties, wind stress curl, and air-sea exchanges. Observations and hindcast simulations suggest that from the early 1970s to the mid-1990s the subpolar gyre became fresher while the gyre and meridional circulations intensified. This is opposite to the relationship of freshening causing a weakened circulation, most often reproduced by climate models. The authors hypothesize that both these configurations exist but dominate on different time scales: a fresher subpolar gyre when the circulation is more intense, at interannual frequencies (configuration A), and a saltier subpolar gyre when the circulation is more intense, at longer periods (configuration B). Rather than going into the detail of the mechanisms sustaining each configuration, the authors' objective is to identify which configuration dominates and to test whether this depends on frequency, in preindustrial control runs of five climate models from phase 5 of the Coupled Model Intercomparison Project (CMIP5). To this end, the authors have developed a novel intercomparison method that enables analysis of freshwater budget and circulation changes in a physical perspective that overcomes model specificities. Lag correlations and a crossspectral analysis between freshwater content changes and circulation indices validate the authors' hypothesis, as configuration $\mathrm{A}$ is only visible at interannual frequencies while configuration $\mathrm{B}$ is mostly visible at decadal and longer periods, suggesting that the driving role of salinity on the circulation depends on frequency. Overall, this analysis underscores the large differences among state-of-the-art climate models in their representations of the North Atlantic freshwater budget.
\end{abstract}

\section{Introduction}

In the last half of the twentieth century, a large-scale decline of salinity in the high-latitude North Atlantic Ocean was observed and perceived to be somewhat extraordinary (Dickson et al. 1988, 2002; Curry et al. 2003; Curry and Mauritzen 2005; Peterson et al. 2006). Dickson et al. (2002) described this phenomenon as "arguably the largest full-depth changes observed in the

Corresponding author address: Julie Deshayes, Department of Oceanography, University of Cape Town, Private Bag X3, Rondebosch 7701, Cape Town, South Africa.

E-mail: julie.deshayes@ird.fr modern instrumental record." Negative salinity anomalies extended to the deep ocean as convection intensified in the Labrador Sea, injecting newly formed fresh Labrador Seawater in the upper $2000 \mathrm{~m}$, and as dense water overflowing through the Nordic Sea sills became fresher (Dickson et al. 2002). In the same time frame, indirect estimates of the circulation strength, based on integrated density anomalies in the Labrador and Sargasso Seas, suggested that the baroclinic circulation intensified from 1970 to 1995 (Curry and McCartney 2001). The intensification of this circulation was associated with a general cooling and subsequent increase in dense water formation that accompanied the freshening (Yashayaev 2007). After more than $30 \mathrm{yr}$, in the mid-1990s, these tendencies 
reversed: the subpolar North Atlantic became warmer and saltier, and the circulation declined (Hakkinen and Rhines 2004; Yashayaev 2007). These starkly contrasting time periods exhibited a clear connection between freshwater (FW) content and circulation strength but are opposite to the expected relationship of freshening causing a weakened circulation.

Hindcast ocean simulations, using realistic configurations of ocean general circulation models (OGCM) forced by atmospheric reanalysis, have been used to describe these modulations of circulation strength and to assess the relationship to salinity anomalies. They confirm that the subpolar gyre and Atlantic meridional overturning circulation (AMOC) intensified concomitantly from the early 1970s to the mid-1990s and decreased thereafter (Hátún et al. 2005; Mauritzen et al. 2006; Deshayes and Frankignoul 2008). These studies also indicate that recent interannual to decadal variability of subpolar gyre circulation was consonant with atmospheric fluctuations of wind and buoyancy forcing. Negative salinity anomalies, which developed in these models consistently with observations, were primarily induced by changes in ocean circulation patterns and intergyre exchanges (Frankignoul et al. 2009), reflecting changes in wind stress curl (Herbaut and Houssais 2009). Salinity anomalies exerted a smaller and opposite influence on upper-ocean density compared to temperature changes, hence barely affecting the circulation (Haak et al. 2003). Dense water formation increased in the subpolar gyre from the early 1970s to the mid-1990s, despite the observed freshening in convective regions, and this induced an intensification of the AMOC (Deshayes and Frankignoul 2008). Thus, hindcast simulations corroborate observations that FW content and circulation strength varied in synchronicity since the 1970s and justify it as a consequence of coherent atmospheric fluctuations that induced both changes concomitantly.

As an investigative tool, hindcast simulations are subject to several drawbacks and limitations. They are commonly forced by reanalysis atmospheric data with large uncertainties because of the low amount of observations available from earlier decades. Salinity drift, a flaw common to all hindcast simulations, is usually corrected by restoring to climatology; this tends to reduce interannual variability. These simulations may exhibit a residual long-term drift and/or a bias of the mean model salinity compared to observations. Finally, lateral fluxes of salt, heat and mass across the lateral boundaries, for regional configurations, are either steady (climatological) or prescribed from a lower-resolution wider simulation. These elements contribute to produce unrealistic deep-water formation and property variability in the simulated ocean. Coupled climate models with freely evolving surface fluxes avoid many of these problems, but they suffer from larger mean biases and they tend to produce a significantly different relationship between the gyre and AMOC circulation and FW anomalies compared to recent observations and hindcast simulations (Frankignoul et al. 2009). In the remainder of this article (and unless specified), circulation refers to both the horizontal subpolar gyre and the AMOC, which are not simply related although both are influenced by the formation of Labrador Seawater. For this reason, they both exhibit an increasing trend from the early 1970s to the mid-1990s, as dense water formation increased (Deshayes and Frankignoul 2008). Still, the deeper part of the subpolar gyre constitutes the deep western boundary current, which composes the deep limb of AMOC. Hence, our study considers both the subpolar gyre and AMOC in parallel, and it is left to another study to investigate the relationship between the two.

Although climate models have been widely used to investigate variability of the AMOC, little consensus regarding causes or consequences of its variability has yet emerged in these models. Still, most coupled models exhibit decadal to multidecadal AMOC fluctuations that involve salinity changes in the regions of dense water formation. In these simulations, salinity exerts a direct influence on ocean circulation: positive salinity anomalies increase density in the subpolar gyre interior, intensify deep convection, and enhance the AMOC, while negative salinity anomalies exert analogous but opposite anomalies. Models differ in how these salinity anomalies occur: through salt import from the subtropics (e.g., Latif et al. 2000; Vellinga and Wu 2004; Mignot and Frankignoul 2005), via sea ice and FW exchanges with the Arctic (e.g., Jungclaus et al. 2005), or locally through enhanced/ diminished air-sea interactions (e.g., Timmermann et al. 1998). The consequent time scales of AMOC variability, ranging from decadal to multidecadal, depend on the model's interaction between convection and AMOC and on the advection time scale for anomalies to reach the convection sites (Swingedouw et al. 2007; Frankcombe and Dijkstra 2011). Despite differences in the details of the mechanisms of variability and in the lag between salinity and circulation changes, a consistent relationship between FW content and AMOC emerges: a fresher subpolar gyre is associated with a weaker AMOC, while a saltier subpolar gyre is linked to a stronger AMOC.

The degree to which FW content and AMOC changes are related in the North Atlantic remains a fundamental question for both past and future climate variability. Paleoclimate research offers persuasive evidence that AMOC and its northward heat transport have undergone extensive reorganizations in the geologic past (e.g., Boyle and Keigwin 1982; Charles and Fairbanks 1992), 
that these changes were linked to episodes of sudden releases of freshwater into the high-latitude Atlantic (e.g., Bond et al. 1992; Broecker 1994; Vidal et al. 1997), and that the climatic impacts were substantial (e.g., Rahmstorf 2002). Among the anticipated consequences of greenhouse warming is that the subpolar seas are expected to freshen as part of a global amplification of hydrological cycles (Meehl et al. 2007) and that AMOC is likely to weaken (Stouffer et al. 2006; Weaver et al. 2012). In the last decade, however, salinity has increased in the subpolar North Atlantic (Hakkinen et al. 2011), and there is no direct evidence of a sustained tendency (decline or intensification) of AMOC (Wunsch and Heimbach 2009) beyond the large seasonal to interannual variability that has been observed (Cunningham et al. 2007). This notwithstanding, recent observations of an increase of the Atlantic multidecadal oscillation index, based on low-frequency large-scale sea surface temperature anomalies (Zhang and Delworth 2006), which may be used as a proxy of AMOC fluctuations (Latif et al. 2006), suggest that AMOC may follow a positive tendency since the early 2000s.

To rationalize the inconsistency between the observation records, hindcast simulations, and coupled climate models, we have investigated the circumstances and time scales of FW content and circulation variability in control run simulations from five state-of-the-art climate models produced for phase 5 of the Coupled Model Intercomparison Project (CMIP5). Overall, our objective is to clarify whether the subpolar gyre is (configuration A) fresher or (configuration B) saltier, at times when the circulation (the AMOC or the subpolar gyre) is more intense. The first configuration, a fresher subpolar gyre as the circulation is more intense, may result from concomitant negative heat content anomalies that intensify horizontal density gradients and hence the circulation (A-1; meridional gradients for the AMOC and offshore-onshore gradients for the subpolar gyre) or concomitant wind forcing that intensifies the AMOC and the subpolar gyre (A-2; mostly at subannual and interannual frequencies; Deshayes and Frankignoul 2008), among other possible mechanisms. The second configuration, a saltier subpolar gyre when the circulation is more intense, may reflect, for example, the direct influence of positive salinity anomalies on density in convective regions (B-1; which dominates the influence of heat content anomalies), inducing more dense water formation and thus intensifying the AMOC and the subpolar gyre circulation, or the advection of positive salinity anomalies from the subtropics by the intensified AMOC (B-2). It remains unclear which configuration dominates, which mechanism causes it, and whether this depends on the time scale of variability. When the atmosphere exhibits persistence, such as the positive North Atlantic Oscillation phases from 1975 to 1995 , mechanisms A-1 and A-2 are likely to add up. Hence, configuration A may dominate a fresher subpolar gyre while at the same time both the subpolar gyre and the AMOC are more intense, as suggested by recent observations and hindcast simulations. The absence of persistent atmospheric forcing is expected at multidecadal and longer frequencies, where atmospheric variability is a white noise. Hence, we expect that configuration $B$, the subpolar gyre being saltier when the circulation is more intense, dominates at those frequencies. Because there is no direct relationship between the subpolar gyre strength and the AMOC, these two circulations may also exhibit a different relationship to FW content in the subpolar gyre.

A first step, as well as the primary objective of this study, is to determine whether both configurations are part of the internal variability of climate model simulations and, if so, whether they operate on preferential time scales and with which circulation preferentially. To this end, we have developed a novel intercomparison method that enables analysis of FW budget and circulation changes in a physical perspective that overcomes model specificities. We applied this methodology to diagnose FW content and circulation changes in the Geophysical Fluid Dynamics Laboratory Climate Model, version 3 (GFDL CM3); the National Center for Atmospheric Research (NCAR) Community Climate System Model, version 4 (CCSM4); the Centre National de Recherches Météorologiques Coupled Global Climate Model, version 5 (CNRM-CM5); the L'Institut Pierre-Simon Laplace Coupled Model, version 5 (IPSL-CM5); and the Max Planck Institute Earth System Model, low resolution (MPI-ESM-LR), on interannual to centennial time scales. It now remains to expand this analysis to other CMIP5 climate models. A secondary objective of this study is an intercomparison of the model FW budgets, in order to evaluate their strengths and weaknesses as tools for investigating past, present, and future climate variability. We found large differences among these models, which is the essential result of this study.

The models, simulations, and intercomparison methods used are described in section 2. Analyses of the subpolar FW budgets diagnosed from each model are presented in section 3, while the relationship between FW content and circulation changes is evaluated in section 4 . The results are discussed in the light of known model biases (section 5) before drawing conclusions (section 6).

\section{Materials and method}

\section{a. Models and simulations}

The simulations that we intercompare follow the requisites of the CMIP5 (for details on the experiment 
TABLE 1. Horizontal resolution of the ocean component of the five climate models: nominal resolution, size of the global ocean grid (latitude $\times$ longitude), and average size of grid cells in the North Atlantic Ocean.

\begin{tabular}{|c|c|c|c|c|c|}
\hline & GFDL & NCAR & IPSL & CNRM & MPI-M \\
\hline Nominal resolution & $1^{\circ}$ & $1^{\circ}$ & $2^{\circ}$ & $1^{\circ}$ & $1.5^{\circ}$ \\
\hline Global ocean & $200 \times 360$ & $384 \times 320$ & $149 \times 182$ & $292 \times 362$ & $220 \times 256$ \\
\hline North Atlantic & $72 \mathrm{~km}$ & $52 \mathrm{~km}$ & $130 \mathrm{~km}$ & $65 \mathrm{~km}$ & $54 \mathrm{~km}$ \\
\hline
\end{tabular}

design, see Taylor et al. 2009). They are integrated from climatological temperature and salinity at rest, for more than $500 \mathrm{yr}$. Nonevolving preindustrial conditions of atmospheric well-mixed gases and aerosol concentrations are imposed, and radiative forcing is kept constant. As these models have been presented in recent publications, we briefly summarize improvements from previous CMIP3 versions and give the horizontal resolution of each ocean component in Table 1 . We limit our discussion to the biases in the North Atlantic that pertain to the present study.

\section{1) GFDL CM3}

GFDL CM3 shares the same ocean and sea ice components as GFDL CM2.1, which was used in the previous CMIP3 project, except that CM3 has a nonlinear free surface (so-called $z^{*}$ model). Recent development efforts have mainly focused on the atmospheric components, including aerosol-cloud interactions, chemistry-climate interactions, and links between the troposphere and stratosphere (Donner et al. 2011). For a discussion of CMIP5 experiments using GFDL CM3, the reader is referred to Griffies et al. (2011). In general, the most recent historical simulations (using radiative forcing from 1860 to 2000) exhibit warm, saline surface biases in the North Atlantic subpolar gyre, juxtaposed with cold, fresh biases offshore of the Grand Banks. The latter is common in simulations where a poorly resolved Gulf Stream separation contributes to downstream shifts in the North Atlantic Current location (e.g., Griffies et al. 2009). Outflows from the Arctic along the East Greenland coast also tend to be fresher in these CM3 simulations and may reflect overly large sea ice extent, which also characterized CM2.1 (though to a larger extent). AMOC is $3-4 \mathrm{~Sv}$ $\left(1 \mathrm{~Sv} \equiv 10^{6} \mathrm{~m}^{3} \mathrm{~s}^{-1}\right)$ more intense in $\mathrm{CM} 3$ compared to CM2.1; however, poleward heat transport is slightly weaker. This is presumably linked to a reduced top-tobottom temperature difference in the simulated fields and to a misrepresentation of the respective contributions of gyre and overturning circulations to the heat transport (Msadek et al. 2013, manuscript submitted to J. Climate). For this study, we investigate the first $600 \mathrm{yr}$ of the 800 -yrlong control simulation (the final $200 \mathrm{yr}$ were not yet available for investigation).

\section{2) NCAR CCSM4}

Gent et al. (2011) describe many improvements from CCSM3 to CCSM4, as well as significant biases that remain in the newer version. Of particular relevance to this study is a new parameterization of overflows that improves the penetration of AMOC and the path of the Gulf Stream (Danabasoglu et al. 2010). This reduces the severity of cold biases off the Grand Banks but does not completely eliminate them (Danabasoglu et al. 2012). The temperature biases in the eastern subpolar North Atlantic switched sign, from negative in CCSM3 to positive in CCSM4. In this study, we investigate the complete 1300-yr-long control simulation and refer to it as the NCAR simulation.

\section{3) CNRM-CM5}

Since its CMIP3 predecessor, the CNRM-CM5 has evolved substantially (Voldoire et al. 2012). Resolution was increased in both atmospheric and oceanic components, the dynamical core of the atmospheric model was revised, and the ocean model was also modified (with the inclusion of partial steps in the bathymetry, a linear free surface, and improvements of the ocean mixed-layer turbulent closure scheme, among others). Climate indices generally improved from CM3 to CM5, but biases remain in CM5 such as an underestimated poleward heat transport and a weak AMOC (while CM3 had an overestimated poleward heat transport and AMOC). As the general warm bias of CM3 was largely reduced in CM5, a cold and fresh bias is dominant offshore of Grand Banks and to the east of the subpolar North Atlantic in CM5. Note that there is a nearly constant negative salinity drift in the control simulation, presumably due to erroneous coupling between sea ice and ocean. We do not include any special statistical treatment in our analysis to remove this drift, but we use time filtering methods to evaluate the relationship between FW changes and circulation for specific time scales; hence this drift is not likely to affect the comparison with the other runs. In this study, we investigate the first $850 \mathrm{yr}$ of the control simulation.

\section{4) IPSL-CM5}

The new version of the IPSL coupled model IPSL-CM5 is a full Earth system model with improved atmospheric 
and oceanic dynamics. Modifications from previous versions have included additional vertical resolution and new parameterizations in the atmosphere, a better representation of the ocean bottom via partial steps, and an improved ocean mixed-layer turbulent closure scheme (Dufresne et al. 2013). As discussed by Escudier et al. (2013), the preindustrial control run exhibits a large-scale cold bias in the North Atlantic, particularly to the east of the Grand Banks. As in other models, this is partly related to a southward shift of the western boundary current system. A cold bias is also found in atmosphere-only simulations of the same model (Guemas and Codron 2011) and has been attributed to unrealistic departures of the jet stream from the coast and a poleward shift of the atmospheric jet. These biases become amplified in coupled mode. An excess of FW forcing over the Labrador Sea and an overestimation of winter sea ice cover both contribute to a strong negative surface salinity bias in the northwestern Atlantic (Swingedouw et al. 2007). These fresh biases are enhanced in the Labrador and Nordic Seas and prevent realistic representations of deep convection in these areas. We analyze here the complete 1000-yr-long control simulation.

\section{5) MPI-ESM-LR}

The most important changes from CMIP3 MPI Ocean Model (MPI-OM)-ECHAM5 model to the CMIP5 MPI-ESM-LR concern the atmosphere compartment, with modifications of the shortwave radiative transfer; the representation of the land surface, including interactive vegetation; and the representation of the middle atmosphere as part of the default configuration, while the ocean compartment did not change apart from technical developments (Jungclaus et al. 2013). Improvements in the simulated climate mainly concern features that are related to those changes, while the biases in the ocean are essentially retained: on the global scale, MPI-ESM-LR gets too warm and saline at intermediate levels and in the deep ocean, presumably due to shortcomings in the parameterization of unresolved eddies and/or spurious numerical mixing as an inherent feature of $z$-level models (e.g., Delworth et al. 2012; Griffies et al. 2009), whereas this model is too cold and fresh in the upper layers. The cold and fresh bias is extreme in the North Atlantic, between $40^{\circ}$ and $50^{\circ} \mathrm{N}$, which is related to the fact that the model produces a North Atlantic Current that is too zonally oriented. This is, in turn, due to the coarse resolution that prevents a proper representation of the Gulf Stream separation, as in the other models. We analyze here the complete 1000-yr-long control simulation and refer to it as the Max Planck Institute for Meteorology (MPI-M) simulation.

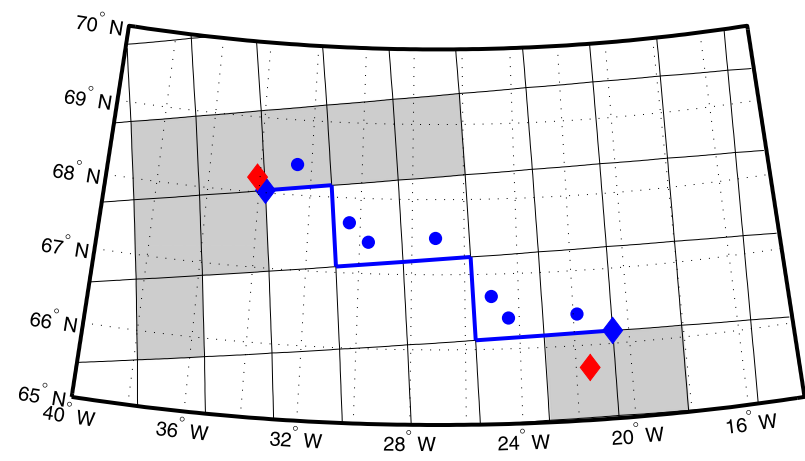

FIG. 1. Construction of a section between Greenland and Iceland in IPSL gridded domain (plain black lines; gray shading locates grid cells in land) using PAGO diagnostic tool: starting from userdefined (latitude, longitude) end points (red diamonds), PAGO locates the nearest grid points (blue diamonds) and connects them as a sequence of grid faces following a great circle pathway between them (blue lines). PAGO specifies the projection of model velocities for each segment of the section (blue dots, located adjacent to the face centers, should be seen as the head of arrows perpendicular to the grid faces, onto which model velocities are projected).

\section{b. PAGO diagnostic tool}

Model diagnostics are usually limited to investigations along grid lines, which may be strongly distorted toward the poles. This is actually the case for the five models studied here: each model has its own type of grid (e.g., the tripolar ORCA grid used by CNRM and IPSL and illustrated in Fig. 1). This presents a serious hindrance to intercomparison studies of models that do not share the same grids and for quantitative comparisons to observations. To surmount the difficulties imposed by differences of model grids, we have developed a suite of tools called Physical Analysis of a Gridded Ocean (PAGO). These tools enable physical sections to be mapped onto an individual model's grid providing a basis for extracting analogous lines and volumes from different grid configurations.

Briefly, for two physical end points delimiting a line or section (identified by their geographical coordinates), PAGO locates the nearest model grid points and connects them as a sequence of grid faces following a great circle pathway between them (Fig. 1). Model data are then extracted at the center of the grid faces. The grid configuration determines the details of the extraction and analysis. For example, $\mathrm{C}$ grid models directly provide the velocity normal to the grid faces at their center. Tracers, originally specified at the center of the grid cells, are interpolated to the center of the grid faces using a first-order centered scheme. The advective terms of the tracer conservation equation are thus constructed very closely to the way they are calculated in the model and hence minimizing the error. For B grid models, 
velocities given at the corners of the grid mesh must be interpolated onto the centers of the grid faces, taking into account scale factors of the grid cells and lateral boundary conditions; this presumably introduces some error in the reconstruction of the advective terms. PAGO automatically defines the direction onto which model velocities must be projected for each segment of the section, in order to have a consistent transport normal to the section (in Fig. 1, blue dots must be located on the same side of the blue line). It is important to emphasize that in our methodology there is no rotation of coordinates or velocities, ensuring the best conservation of volume (within the uncertainty imposed by eventual data compression). PAGO implements a tailored method to select all grid cells within an area (e.g., enclosed by land or by PAGO sections). The convergence of tracers into the region of interest is calculated as the sum of the transport normal to the open boundaries.

An analysis of ocean variability on interannual to multidecadal time scales requires monthly or yearly model output spanning centennial-long simulations. This may represent massive amounts of data that cannot be quickly loaded or easily stored on a personal computer. A strategy was developed to upload the fourdimensional model output within a restricted domain and save temperature, salinity, and horizontal velocities along a suite of predefined physical sections, as threedimensional variables. Variability of the model output is further synthesized with computation of time indices reflecting the volume, heat, and salt transport across the sections. These indices include the net, overturning (in depth and density space), and gyre components, as well as vertical integrals over selected depths or densities. They are calculated at each time slice of the original model output (daily, monthly, or yearly). Note that tracer transports and indices in density space should preferentially be calculated from model outputs at the highest frequency, to avoid errors due to missing correlations between tracer and velocity fields. Similarly, for volumetric estimates of property content changes, the upload of a four-dimensional model output is restricted to specifically defined areas and property content changes are computed and stored for each time slice. It then becomes easy to analyze variability of the various circulation components, for volume and tracers, and tracer changes on interannual to multidecadal time scales.

As all CMIP5 simulations are freely available to the public, PAGO was conceived as a communal diagnostic tool to facilitate model intercomparisons. We claim that PAGO is a robust tool for model intercomparison because the physical quantities are independent of the model grid (type and resolution) or parameters and do not depend upon a preliminary interpretation of the

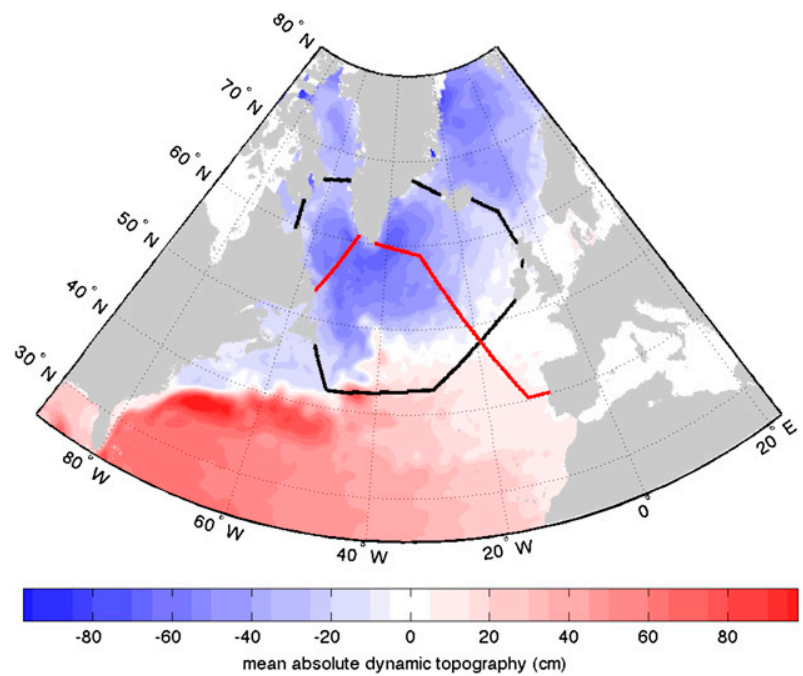

FIG. 2. Definition of the North Atlantic subpolar region used in the paper (within the black lines). Also shown is AR7W section across the Labrador Sea and the OVIDE section across the eastern subpolar gyre (red lines). Background color is the observed mean absolute dynamic topography for 1993-2009.

model circulation and hydrography. PAGO is presently coded for MATLAB software. All programs are available online (from http://www.whoi.edu/science/PO/ pago/). This analysis utilizes a subset of quantities offered by PAGO; we show only the diagnostics that are relevant for the full-depth FW budget in the subpolar North Atlantic.

As in previous studies (e.g., Cuny et al. 2005), a reference salinity of 34.8 has been used to calculate FW content and transport. The relevance of this choice remains under debate (Talley 2008; Treguier et al. 2012); hence, we repeated all calculations using as a reference the time-mean salinity averaged over the region of interest specific to each simulation. Because our results were not affected by the choice of salinity reference, we only show them for the common 34.8 salinity reference. FW transports are expressed with units of volume transports in milliSverdrups $\left(\mathrm{mSv} ; 1 \mathrm{mSv}=10^{3} \mathrm{~m}^{3} \mathrm{~s}^{-1}\right)$, while actual volume transports (e.g., AMOC or subpolar gyre strength) are given in Sverdrups. The sections used in this study contour the subpolar North Atlantic: closing the overflows and straits to the north and west and following the boundary between subpolar and subtropical gyres according to observed dynamic topography (so-called section $42 \mathrm{~N}$; Fig. 2). Ice is not considered separately in any FW content or transport calculations; rather, its influence on the FW budget is lumped with other surface fluxes.

\section{c. Preliminary hydrographic comparison}

Before analyzing the FW budget in details, we present a preliminary comparison of the hydrography and 
circulation in the subpolar gyre. Following PAGO strategy, these characteristics are shown along a section which crosses the Labrador Sea, the Irminger Sea, the Iceland Basin, and the eastern subpolar gyre [a combination of the World Ocean Circulation Experiment (WOCE) AR7W line and Observatoire de la Variabilité Interannuelle et Décennale (OVIDE) sections that were repeatedly monitored; shown in red in Fig. 2]. As a reference, sections of temperature and salinity from the observed HYDROBASE climatology are included. The subpolar gyre circulation is illustrated by the current speed normal to this section, focusing on the Labrador and Irminger Seas.

Along the AR7W/OVIDE section, all five models exhibit an eastward progression from vertically uniform fresh and cold water masses in the Labrador Sea to strongly stratified conditions, with warmer and saltier upper-ocean waters originating in the subtropics, as observed (Fig. 3). Beyond this general large-scale contrast between subpolar and subtropical conditions, the structure and location of thermal and haline fronts differ greatly among models. In the GFDL simulation, the subpolar front is located in the middle of the Irminger Sea (near $36^{\circ} \mathrm{W}$ ) and the main stratification in the subtropics occurs around $2000 \mathrm{~m}$. In CNRM, the subtropical waters are comparatively restricted to the upper $1000 \mathrm{~m}$ along the eastern boundary. NCAR, IPSL, and MPI-M property distributions fall roughly between those two extremes. In IPSL, a pronounced fresh and cold cap covers the Labrador and Irminger Seas and presumably leads to dense water formation south of Iceland and southeast of the Labrador Sea $\left(50^{\circ}-55^{\circ} \mathrm{N}\right.$, $30^{\circ}-45^{\circ} \mathrm{W}$; see Escudier et al. 2013, their Fig. 2).

All models clearly exhibit a cyclonic subpolar gyre made of the East Greenland Current (EGC) in the Irminger Sea and the West Greenland Current and the Labrador Current (LC) in the Labrador Sea (Fig. 4; the apparent bilobar structure of EGC in NCAR and LC in MPI-M is due to the construction of the section as staircases; see Fig. 1). That notwithstanding, the intensity and vertical structure of the currents is largely model dependent. Current speed is minimal in the IPSL model (less than $5 \mathrm{~cm} \mathrm{~s}^{-1}$, except near the surface in the East Greenland Current; Figs. 4e,f) and maximum in NCAR (Figs. 4c,d) and MPI-M (Figs. 4i,j), where it exceeds $15 \mathrm{~cm} \mathrm{~s}^{-1}$. The latter is consistent with estimates based on observations across the Labrador Sea (e.g., Pickart and Spall 2007; Hall et al. 2013), suggesting that GFDL, IPSL and CNRM underestimate the intensity of the circulation in the subpolar gyre. This will be confirmed later by intercomparing the subpolar gyre strength (section 4a). Regarding the vertical extent of the subpolar gyre, the mean $0 \mathrm{~cm} \mathrm{~s}^{-1}$ isotach shows that the currents penetrate down to the bottom in both the Labrador and Irminger Seas, suggesting a quasi-barotropic nature of the subpolar gyre, in all five models. Still, the rate at which the current speed decreases with depth depends on the model. While the currents in NCAR are very uniform in the vertical direction, which is the most consistent with observations, they are largely concentrated in the upper ocean in IPSL (Figs. 4e,f) and in the Labrador Sea in GFDL (Fig. 4a). As a consequence, it is not a straightforward matter to define a maximum depth for the subpolar gyre common to all models, other than the sea floor.

This preliminary comparison already highlights substantial differences among models. These are also very different in their subpolar gyre and overturning circulation strengths, which are presented hereafter (section 4a).

\section{Subpolar freshwater budget}

Analyses of subpolar gyre FW budgets in each of the five control simulations are synthesized by the mean and variance for each term in the budget (Table 2) and the power spectra of variability (Fig. 5). It is immediately clear that the details of these budgets are strongly model dependent in amplitude and source (i.e., lateral advection versus surface fluxes).

Monthly FW content was integrated within the subpolar gyre region (shown in Fig. 2) from the surface down to the bottom. Interannual variability in $\mathrm{FW}$ content changes is estimated as the difference between two successive months of January. As the model simulations approached steady state, yearly changes in FW content generally averaged to 0 (Table 2 ), with the exception of CNRM, where inconsistencies in sea iceocean fluxes induced a global freshening (Voldoire et al. 2012). The standard deviation of FW content changes, which reflects the range of variability in the FW budget depends on the model, varying from $30 \mathrm{mSv}$ in NCAR to $84 \mathrm{mSv}$ in GFDL.

Changes in FW content can be attributed to combinations of (i) surface fluxes of FW and (ii) advective and (iii) diffusive fluxes of $\mathrm{FW}$ at the lateral boundaries of the domain. Using PAGO, we have integrated advective fluxes across all lateral boundaries of the subpolar gyre and calculated yearly averages, which we call FW convergence. Although all models export FW out of the subpolar gyre, mean convergence differs by a factor 2 : from $-68 \mathrm{mSv}$ in CNRM to $-133 \mathrm{mSv}$ in GFDL (Table 2). Standard deviations of FW convergence also largely differ among models, ranging from $31 \mathrm{mSv}$ in NCAR to $121 \mathrm{mSv}$ in MPI-M. FW convergence is the sum of two main contributions: FW transport across overflows and across section $42 \mathrm{~N}$. In all models, FW transport across 

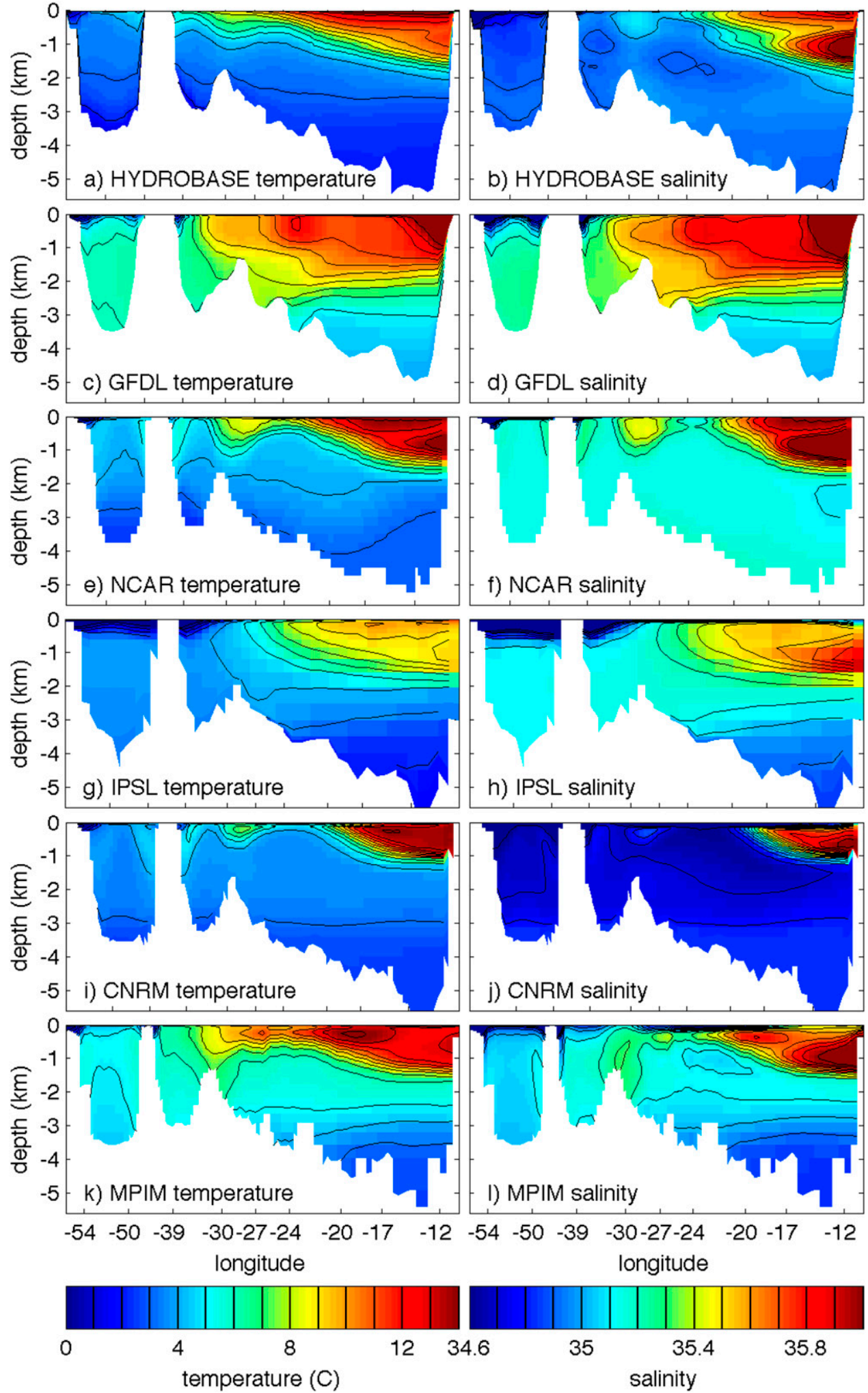

FIG. 3. Temperature and salinity (a),(b) in observations and (c)-(1) in CMIP5 climate models along AR7W/OVIDE section (red line in Fig. 2). Climate model data are taken $500 \mathrm{yr}$ after the beginning of the simulation, averaged over $100 \mathrm{yr}$. 


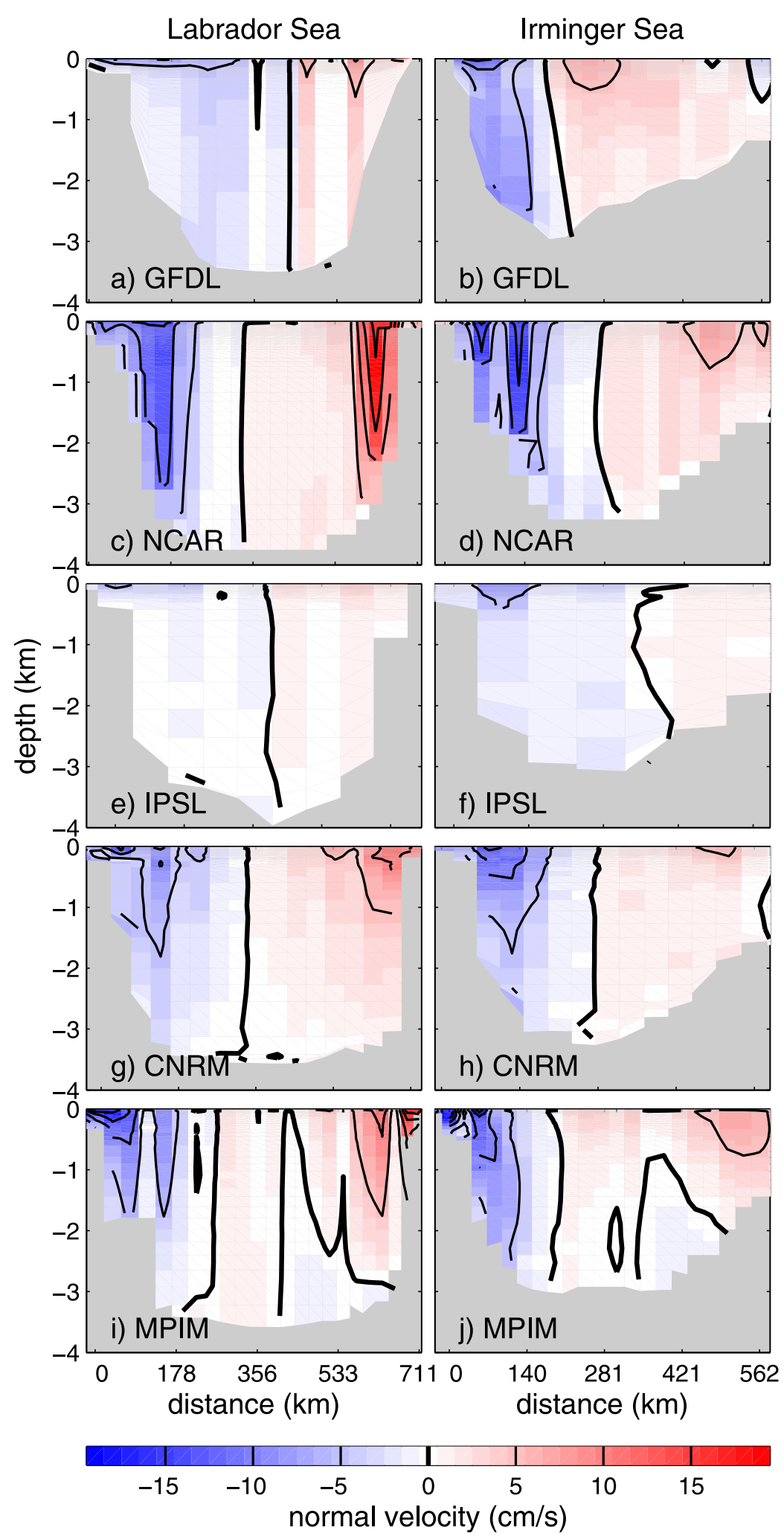

FIG. 4. Current speed normal to sections (left) AR7W and (right) OVIDE in CMIP5 climate models (positive northward and negative southward). Climate model data are taken $500 \mathrm{yr}$ after the beginning of the simulation, averaged over $100 \mathrm{yr}$. 
TABLE 2. Subpolar gyre freshwater budget in CMIP5 climate models (see text for details; mean and standard deviation given in mSv, except for correlations that have no unit). FW content changes are calculated from one year to the other, based on volumetric censuses in January. FW transports are defined positive southward, calculated on the monthly outputs but averaged every year. Note that there are other advective terms that contribute to FW convergence (e.g., transport through Hudson Strait to Baffin Bay and through the Irish Channel), other than the two mentioned in the table. The last section of the table gives the correlation between FW content changes on the one hand and FW convergence or FW residual on the other hand.

\begin{tabular}{|c|c|c|c|c|c|}
\hline & GFDL & NCAR & IPSL & CNRM & MPI-M \\
\hline FW content changes & $-1 \pm 84$ & $1 \pm 30$ & $0 \pm 43$ & $4 \pm 40$ & $0 \pm 55$ \\
\hline FW convergence & $-133 \pm 80$ & $-89 \pm 31$ & $-88 \pm 54$ & $-68 \pm 39$ & $-69 \pm 121$ \\
\hline FW transport across overflows & $251 \pm 26$ & $184 \pm 11$ & $173 \pm 19$ & $128 \pm 22$ & $180 \pm 19$ \\
\hline FW transport across section $42 \mathrm{~N}$ & $458 \pm 69$ & $385 \pm 27$ & $303 \pm 46$ & $368 \pm 32$ & $383 \pm 118$ \\
\hline $\begin{array}{l}\text { FW residual } \\
\text { correlation with... }\end{array}$ & $132 \pm 15$ & $89 \pm 28$ & $88 \pm 27$ & $72 \pm 15$ & $69 \pm 103$ \\
\hline FW convergence & 0.99 & 0.58 & 0.86 & 0.93 & 0.52 \\
\hline FW residual & 0.34 & 0.44 & -0.10 & 0.23 & -0.07 \\
\hline
\end{tabular}

section $42 \mathrm{~N}$ exhibits the largest mean and standard deviation, suggesting that $\mathrm{FW}$ exchanges through that section dominate the net FW convergence to the subpolar gyre, for the mean state and the fluctuations. Another advective contribution to FW content in the subpolar gyre is FW transport from Baffin and Hudson Bays (not shown). In CNRM, it is of the same order of magnitude as FW transport across overflows and hence much smaller than FW transport across section $42 \mathrm{~N}$. In the other four models, this contribution is much smaller than FW transport across overflows, particularly in IPSL, which lacks a connection between the Arctic and the subpolar gyre through the Canadian Archipelago. Note that, overall, GFDL transports run $20 \%-50 \%$ above the other models. Estimates of FW transport across section $42 \mathrm{~N}$ by Talley (2008), using historical observations, range between 380 and $400 \mathrm{mSv}$. Hence, to the limit that these observations are representative of long-term mean FW circulation in the North Atlantic, FW transport may be overestimated in GFDL and underestimated in IPSL. No estimate of FW transport across overflows has been drawn from observations; hence, we cannot assess the realism of simulated FW convergence. We cannot assess, either, the realism of the variability of $\mathrm{FW}$ transport across section $42 \mathrm{~N}$, which varies by up to a factor of 5 .

The difference between changes in FW content and FW convergence combines the effects of lateral diffusion and surface fluxes [evaporation $(E)$, precipitation $(P)$, runoff $(R)$, and sea ice contributions], and this FW residual has been calculated on a yearly basis. Although the mean provides little additional information about the FW budget, the range of variability indicates the extent to which changes in FW content are due to convergence or surface fluxes/lateral diffusion. Note that Table 2 gives the standard deviation of each term, but it is the sum of the variance of FW convergence, the variance of the residual fluxes, and twice the covariance between FW convergence and residual fluxes, which amounts to the variance of FW content changes. In three models (GFDL, IPSL and CNRM), the variance of FW residual is small compared to that of $\mathrm{FW}$ convergence (Table 2). This indicates that surface fluxes and lateral diffusion together play a lesser role in driving changes in FW content, compared to changes in advection across lateral boundaries. It is consistent with the correlation between changes in FW content and FW convergence, which exceeds 0.86 in these three models, while correlation between changes in FW content and FW residual is much smaller. In this respect, NCAR and MPI-M stand apart from the other models: the variances of FW residual and FW convergence are of comparable magnitude and the correlation between changes in FW content and FW convergence decreases to 0.5. Thus, in NCAR and MPI-M, FW convergence and FW surface fluxes (together with lateral diffusion) appear to be equally important in driving changes in FW content.

In the absence of fully resolved mesoscale processes, their contribution to tracer advection is parameterized as an advective flux by eddy-induced velocities [a.k.a. Gent-McWilliams (GM) parameterization; Gent and McWilliams 1990; Treguier et al. 1997]. In some models, these parameters are available for offline diagnostics. In IPSL, this contribution has been evaluated explicitly and compared to the advective flux of FW based on Eulerian velocities. This contribution was found to be negligible for North Atlantic FW transports presented in this study (this may not be the case outside of the study region or for other sections). Because the other models employ the same parameterization (NCAR additionally includes a parameterization of submesoscale processes), we have assumed that this condition applies equally to all of them. Hence, in this paper the advective transports of FW are solely a consequence of the Eulerian velocity 


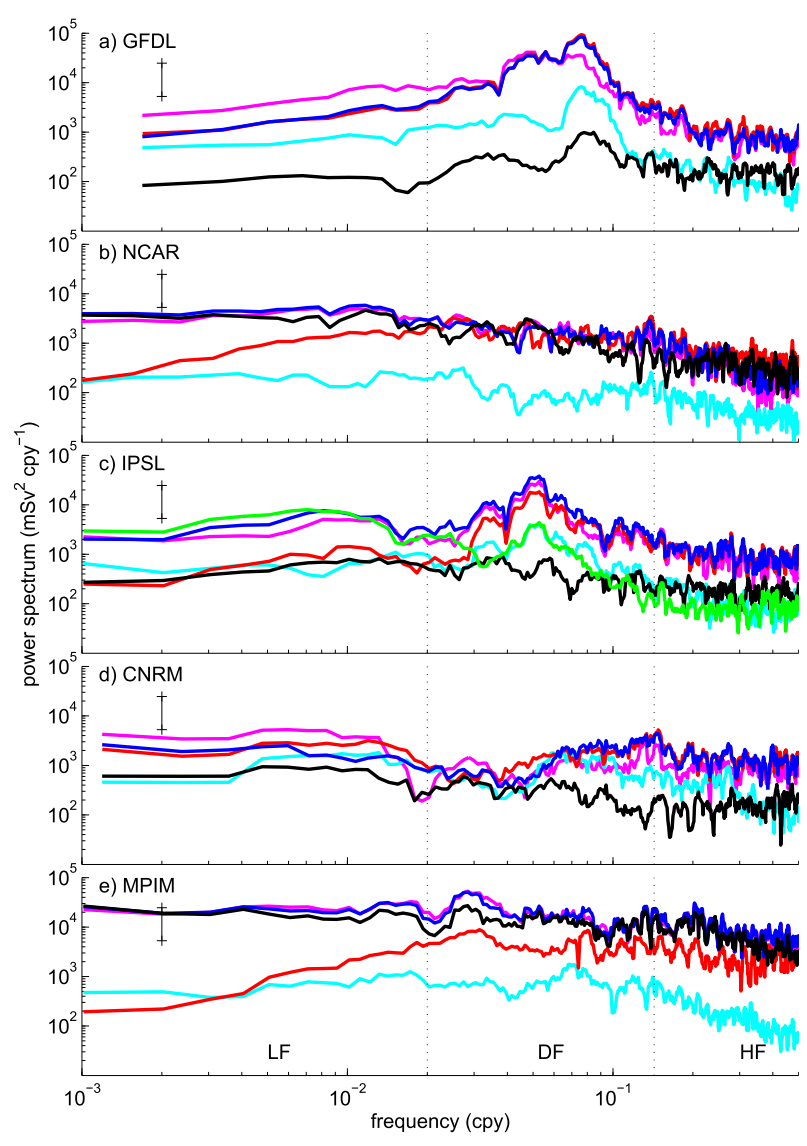

FIG. 5. Power spectra of the subpolar gyre FW budget in CMIP5 climate models: FW content changes (red); convergence (blue); and residual (black), which includes surface fluxes and lateral diffusion. For the IPSL model, surface fluxes (black) are diagnosed separately from lateral diffusion (green). FW convergence is further decomposed into the net FW transport through section $42 \mathrm{~N}$ : that is, the southern boundary of the subpolar gyre (pink) and through overflows (cyan). All spectra are estimated using a multitaper method with seven windows. The $95 \%$ confidence interval for each spectrum estimation is indicated at $2 \times 10^{-3}$ cpy (based on a chi-squared method).

field, and the GM parameterized advection is lumped together with the residual: that is, surface fluxes, diffusion, and sea ice exchanges.

The dominant time scales of variability are obtained by examining the power spectrum for each term in $\mathrm{FW}$ budget. GFDL and IPSL both exhibit peaks at decadal frequencies (at 12- and 20-yr periods, respectively), whereas no dominant time scale emerges in NCAR, CNRM, or MPI-M (Fig. 5). These spectra confirm the results shown in Table 2. That is, in GFDL, IPSL and CNRM, spectra of FW convergence (blue lines) nearly coincide with those depicting FW content changes (red lines) at interannual to multidecadal frequencies but are uniformly larger than spectra for FW residual (black lines). This implies that changes in FW content and FW convergence are very closely related on those time scales. In NCAR, spectra of FW content and FW convergence are similar in amplitude to FW residual, suggesting that the latter is equally important as advection in driving changes in FW content. In MPI-M, spectra of FW convergence and FW residual nearly coincide, whereas the spectrum of FW content is systematically lower, in particular at low frequency (multidecadal and longer time scales). Hence, in the latter model FW convergence directly reflects surface fluxes (and other contributions to the residual), while FW storage in the subpolar gyre plays a lesser role in FW budget.

To assess the relative importance of surface and diffusive lateral fluxes, we have evaluated all surface FW fluxes in IPSL separately (Fig. 5c, black line) to yield an estimate of diffusion fluxes as the residual of the other terms (green line). Diffusion fluxes exhibit the smallest variance of all fluxes at interannual frequencies, with increasing variance at longer time scales that implies an equilibrium between advection and diffusion at lower frequencies (multidecadal and longer). We also show, in Fig. 5, spectra of variability for FW transport across overflows (cyan) and across section $42 \mathrm{~N}$ (pink). At all frequencies, the latter exceeds the former, except in CNRM, where the two spectra have similar amplitude and cross each other several times.

As a general conclusion, it is evident that FW budgets vary greatly among these state-of-the-art climate models. The means and standard deviations of each term vary by more than a factor of 2 . Two of the models exhibit enhanced variability at decadal frequencies, while the power spectra of the other models are flat with no dominant time scale of variability. In three of the five models, advective convergence governs changes in FW content, with surface fluxes and diffusion having lesser impact at interannual to decadal frequencies. On multidecadal time scales, diffusion becomes important (at least in IPSL). The other two models are remarkably different in this regard: FW surface fluxes (and other contributions to the residual) play a much larger role in the FW budget.

\section{Link with North Atlantic circulation}

A principal question that we address in this study is the relationship between FW content in the subpolar gyre and circulation changes in the North Atlantic, of both the AMOC and the subpolar gyre. We have already shown that convergence of FW is an important contributor to FW content changes in all models. Based on this result and to the extent that changes in FW transport are correlated with changes in circulation strength, circulation changes are expected to exert a significant influence on FW content. On the other hand, FW content 
TABLE 3. Circulation indices in CMIP5 climate models: subpolar gyre (barotropic circulation along the eastern coast of Greenland, across OVIDE section; i.e., red line in Fig. 2) and meridional overturning circulation at section $42 \mathrm{~N}$ (overturning volume transport across the southern boundary of subpolar gyre). Mean and standard deviation (in Sv) of annual indices are calculated over $100 \mathrm{yr}, 500 \mathrm{yr}$ after the beginning of each simulation.

\begin{tabular}{|c|c|c|c|c|c|}
\hline & GFDL & NCAR & IPSL & CNRM & MPI-M \\
\hline Subpolar gyre & $27.92 \pm 2.86$ & $40.53 \pm 1.78$ & $16.28 \pm 2.99$ & $26.10 \pm 1.27$ & $26.5 \pm 3.21$ \\
\hline $\mathrm{AMOC}$ at section $42 \mathrm{~N}$ & $24.41 \pm 1.96$ & $21.84 \pm 1.12$ & $8.57 \pm 1.03$ & $8.97 \pm 1.00$ & $16.23 \pm 2.81$ \\
\hline
\end{tabular}

changes may have an impact on the circulation strength, via density anomalies. Rather than determining all the mechanisms that relate FW content and circulation changes in each simulation, our objective is to clarify whether the subpolar gyre is fresher or saltier at times when the circulation is more intense. Because any causal relationship may imply a specific adjustment time scale, we describe in the following the lag correlations between FW content changes and circulation indices. We also diagnose the phase of the covariance between those indices, in order to emphasize how these results depend on frequency. To begin with, we introduce the circulation indices describing the subpolar gyre strength and AMOC that we use subsequently.

\section{a. North Atlantic circulation indices}

Subpolar gyre strength is usually estimated as the maximum barotropic streamfunction. Such a diagnosis is not available from PAGO, which only sees circulation normal to selected sections. Rather, we make use of the fact that the subpolar gyre circulation is confined to narrow boundary currents on its western boundaries: namely, the EGC and the LC. Hence we estimate the subpolar gyre strength each year as the maximum barotropic transport normal to sections AR7W and OVIDE (red lines in Fig. 2), accumulated from the coast offshore. Because the two sections go through the central Irminger and Labrador Seas, where the barotropic streamfunction is maximal, our method is qualitatively similar to classical indices of the subpolar gyre strength.

Table 3 gives the mean and standard deviation of the barotropic transport within EGC (across the OVIDE section) for each simulation. Barotropic transport across the southwestern part of AR7W section yields similar numbers (not shown). The mean subpolar gyre strength differs greatly among models, from $16 \mathrm{~Sv}$ in IPSL to $40 \mathrm{~Sv}$ in NCAR, while GFDL, CNRM, and MPI-M weigh in at approximately $26-28 \mathrm{~Sv}$. The estimated strength of the subpolar gyre based on observations ranges between 34 and 40 Sv (Clarke 1984; Reynaud et al. 1995; note that the method employed to estimate the subpolar gyre strength based on observations is actually the same as the one we use here). Standard deviations of these transports range between 1 and $3 \mathrm{~Sv}$, which is small compared to the range of mean values of the subpolar gyre strength. These ranges suggest a simple characterization for the subpolar gyre strength in these simulations as either (i) very weak (IPSL), (ii) weak (GFDL, CNRM, and MPI-M), or (iii) standard (NCAR).

The strength of the AMOC is estimated at section $42 \mathrm{~N}$ as the maximum cumulative normal transport from the surface downward. As the section is not zonal, this definition differs from the classical AMOC index (e.g., Deshayes and Frankignoul 2008). Nonetheless, the values obtained here are very similar to those published in the reference papers describing the control simulations, based on classical definitions (Griffies et al. 2011; Danabasoglu et al. 2012; Voldoire et al. 2012; Escudier et al. 2013; Jungclaus et al. 2013). Our choice to monitor AMOC with this method is motivated by the consistency with the overturning component of $\mathrm{FW}$ transport at section $42 \mathrm{~N}$, which is useful to better understand the link between AMOC and FW content in the subpolar gyre. The mean AMOC ranges from 9Sv for IPSL and CNRM to 22-24 Sv for GFDL and NCAR, with MPI-M standing in between at $16 \mathrm{~Sv}$ (Table 3)-another strikingly large range of values - with similar and small standard deviation in all models of about $1-3 \mathrm{~Sv}$. We will characterize these relative states of AMOC as (i) weak (IPSL and CNRM), (ii) medium (MPI-M), and (iii) strong (NCAR and GFDL). There is no direct estimate of AMOC strength at this latitude, but it is worthwhile mentioning the observational estimate of $18.7 \pm 4.8 \mathrm{~Sv}$ at $26^{\circ} \mathrm{N}$ (Rayner et al. 2011).

There is no simple relationship between the subpolar gyre strength and the AMOC. The latter is related to dense water formation, which takes place in the center of the subpolar gyre and the Nordic Seas, but it remains unclear what primarily sets the mean amplitude of AMOC among all possible drivers (for a review of those drivers, see Kuhlbrodt et al. 2007). The subpolar gyre is primarily driven by wind forcing, but stratification at depth, maintained by either local dense water formation or the overflow of dense water from the Nordic Seas, in interaction with the sloping bottom (Hallberg and Rhines 1996), also controls its amplitude. We made use of the circulation indices calculated here to check whether there is a simple relationship between the mean 
subpolar gyre strength and AMOC in the models that we analyzed. Both circulations are underestimated in IPSL and CNRM, both are vigorous in NCAR, and both are in the middle of the range in MPI-M. On the other hand, GFDL represents a complex combination of a strong AMOC and a weak subpolar gyre. Investigating the dynamical factors that determine these differences is beyond the scope of this paper. However, we noted of another similar/dissimilar tendency. Similar to the time variability of FW content, GFDL and IPSL show enhanced circulation variability at decadal frequencies (at 12- and 20-yr periods, respectively), while NCAR, CNRM, and MPI-M show no preferential time scale of variability (not shown). Strikingly, although GFDL and IPSL both have pronounced decadal variability, their mean circulation strengths are quite different [IPSL: 16 (gyre) and 9Sv (AMOC); GFDL: 26 (gyre) and $22 \mathrm{~Sv}$ (AMOC)].

\section{b. Correlation between freshwater content and circulation}

Next, we correlated the annual time series of FW content changes with circulation indices (Fig. 6). To maximize the significance of those correlations, time series span the entire period analyzed for each simulation. Hanning filters were applied to separately consider (i) interannual frequencies (HF; periods smaller than $7 \mathrm{yr}$ ), (ii) decadal frequencies (DF; periods ranging from 7 to $50 \mathrm{yr}$ ), and (iii) multidecadal frequencies (LF; periods longer than $50 \mathrm{yr}$ ). The cutoff frequencies were chosen to isolate the peak of enhanced variability in GFDL and IPSL into DF periods (cutoff frequencies are indicated with dotted lines in Fig. 5). The significance level uses a number of degrees of freedom that depends on the autocorrelation at lag 1 of the time series (which is particularly large for low-pass-filtered indices), following Bretherton et al. [1999, their Eq. (31)]. Hence, the level of significance is the lowest in LF and the highest in HF (i.e., the uncertainty band is the largest in LF and the smallest in HF).

\section{1) INTERANNUAL FREQUENCY}

In GFDL, the FW content and the subpolar gyre monitored in the Irminger Sea are positively correlated at interannual frequencies (Fig. 6a, dark green line): that is, the subpolar gyre strengthens as it becomes fresher. When the subpolar gyre is monitored in the Labrador Sea, correlation is also positive but at its maximum when FW content leads by $2 \mathrm{yr}$ (light green line). This 2-yr lag shift corresponds to a 2-yr phase lag between subpolar gyre fluctuations in the Irminger (leading) and Labrador Seas. Deshayes and Frankignoul (2008), using a hindcast simulation, already described such a phase lag in subpolar gyre fluctuations and attributed it to baroclinic current anomalies in the Labrador Current due to local wind stress curl anomalies. The concomitant increases of FW content and the subpolar gyre strength are consistent with recent observations (Hakkinen et al. 2011) and hindcast simulations (Frankignoul et al. 2009), which suggest that both are driven by interannual fluctuations of atmospheric forcing. A similar mechanism is visible in MPI-M (Fig. $6 \mathrm{~m}$ ) and CNRM (Fig. 6j) when FW content leads the subpolar gyre strength by $1 \mathrm{yr}$; however, it is absent in NCAR (Fig. 6d) and IPSL (Fig. 6g) at interannual frequencies. At positive lags, FW content and the subpolar gyre strength are negatively correlated in all simulations but MPI-M, with the largest absolute correlation in GFDL when the circulation leads by $3-5 \mathrm{yr}$. In all simulations, the strengthening of the subpolar gyre increases the northward salt transport across section $42 \mathrm{~N}$ (not shown). As a result, freshening of subpolar gyre in GFDL and CNRM, which is concomitant with or precedes its strengthening, reverses to salinification a few years later.

Correlations between FW content and AMOC are more straightforward (Fig. 6, orange lines): large, negative, and in phase in GFDL and NCAR, reflecting an increased northward salt transport associated with intensification of AMOC (not shown) that reduces FW content in the subpolar gyre. Besides the large negative peak in phase, GFDL shows positive correlations at a \pm 6 -yr lag, which are remnants of the 12 -yr periodic cycle (see below). NCAR also shows positive correlations at a \pm 2 -yr lag, but those are hardly significant. Correlations between FW content and AMOC are much smaller in CNRM, at maximum and negative when AMOC leads by $1 \mathrm{yr}$, and hardly significant in IPSL and MPI-M.

\section{2) DECADAL FREQUENCY}

At decadal frequencies, correlations between $\mathrm{FW}$ content and circulation changes exhibit oscillatory behavior in GFDL and IPSL (Figs. 6b,h), reflecting the decadal variability in these simulations (Figs. 5a,c). They are negative in phase or at short positive lags, positive at larger (negative and positive) lags, and change sign again at even larger lags. They reflect a cyclic behavior for FW content and circulation anomalies: as circulation is more intense, FW content decreases, which leads to a decrease in circulation intensity hence an increase in FW content and so on. The time lag between each stage of this cycle is $3-5 \mathrm{yr}$ (one quarter of the duration of the full cycle, consistent with peaks in spectra). Additional covariance analysis shows that circulation anomalies influence FW content via anomalous salt transport across 

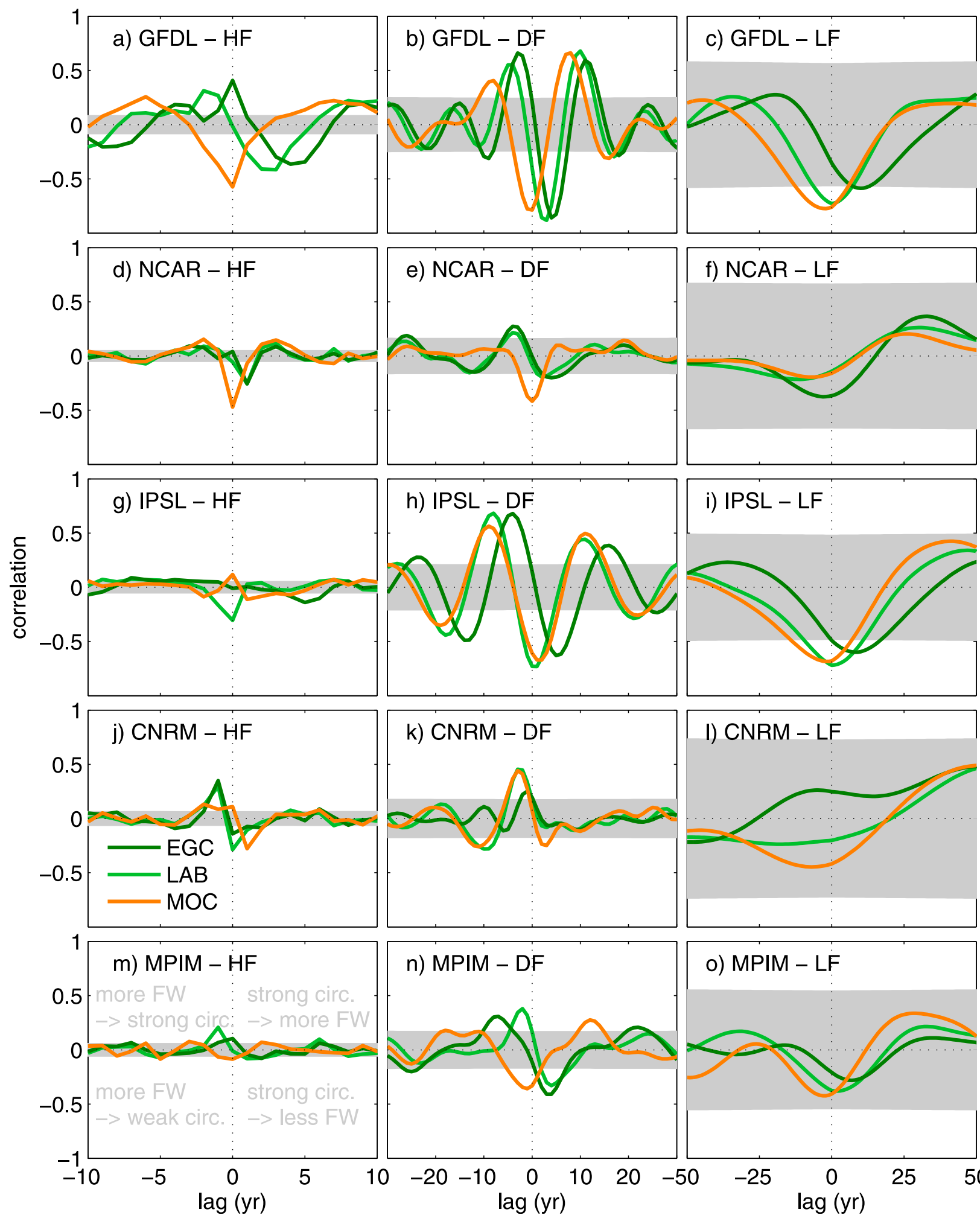

o) MPIM - LF

FIG. 6. Correlation between freshwater content changes and AMOC (orange lines), subpolar gyre strength in the Irminger Sea (dark green lines) and in the Labrador Sea (light green lines) in CMIP5 climate models, at HF (time series are high-pass filtered with Hanning window and 7-yr cutoff period), DF (time series are bandpass filtered with 7- and 50-yr cutoff periods), and LF (time series are low-pass filtered with 50-yr cutoff periods). Freshwater content changes lead for negative lags. Gray shading indicates $5 \%$ significance levels, which take into account the autocorrelation of the time series. 
section 42N: intensification of both MOC and subpolar gyre circulation leads to an increase in northward salt transport and hence a decrease in FW content.

Identical to the interannual frequency, GFDL correlations with the subpolar gyre strength exhibit a phase lag from the Irminger to the Labrador Sea. Similarly, IPSL correlations are lag shifted from the Irminger to the Labrador Sea, albeit with a slightly larger shift. Following the hypothesis of Deshayes and Frankignoul (2008), this difference in phase shift may be due to differences in wind stress curl patterns. It may also reflect the impact of model discretization (GFDL uses a B grid while IPSL uses a $\mathrm{C}$ grid) on wave propagation time scales (e.g., Hsieh et al. 1983).

In NCAR, CNRM, and MPI-M, the correlation between the subpolar gyre strength and FW content is positive at negative lags, suggesting that an increase in FW content leads to an intensification of the subpolar gyre (Figs. 6e,k,n). Correlations at positive lags, which are hardly significant except in MPI-M, suggest that an increase in the subpolar gyre strength leads to a decrease in FW content, as described in IPSL and GFDL.

In NCAR and MPI-M, correlation with AMOC is negative in phase, reflecting that an intensification of AMOC coincides with a decrease in FW content. By contrast, in CNRM correlation is positive when FW leads by a few years, indicating that an increase in $\mathrm{FW}$ content leads to an intensification in AMOC.

\section{3) MultideCADAl FREQUENCY}

At multidecadal frequencies, the level of uncertainty increases dramatically and correlations are only significant in GFDL and IPSL (Figs. 6c,i). In both simulations and for both circulations, the correlation is negative, reflecting the increased northward salt transport associated with the increase in circulation strength. For AMOC in GFDL, the correlation peak is slightly shifted toward negative lags. This indicates that a decrease in FW content (i.e., an increase in subpolar gyre salinity) tends to precede the intensification of AMOC. However, considering the autocorrelation of these low-pass-filtered indices, it is unlikely that this time lag is significant. Otherwise (i.e., for AMOC in IPSL and for the subpolar gyre in GFDL and IPSL), the correlation peaks in phase or at positive lags, particularly for the subpolar gyre in the Irminger Sea, although the correlation is weaker. Correlations between circulation and FW content are not significant in NCAR, CNRM, or MPI-M (Figs. 6f,1,o).

\section{4) SYNTHESIS}

Relationships between FW content and circulation obtained with the lag correlations differ among models but illustrate the two configurations described in the introduction. All simulations exhibit a decrease in FW content induced by a strengthened circulation, via a decrease in FW transport or an increase in salt transport at the southern boundary of the subpolar gyre (and vice versa: a decrease in circulation leads to an increase in FW content). This refers to configuration B described in the introduction. Both the subpolar gyre and the AMOC produce such an effect, although with a different lag: the correlation between FW content changes and AMOC is mostly in phase, while the subpolar gyre strength leads FW content changes by up to $5 \mathrm{yr}$. This situation is visible at all frequencies, but not in all models. Besides, FW content is generally larger before AMOC and the subpolar gyre intensify, which refers to configuration A. This is visible at interannual and decadal frequencies, in nearly all simulations. The latter is, presumably, indirect: both anomalies are likely to be forced by concurrent atmospheric anomalies. It is beyond the scope of this paper to clarify this mechanism further. Rather, we clarify how these two configurations, A and B, depend on frequency, by analyzing the phase of the cross-spectra.

\section{c. Cross-spectral analysis}

We further explore the frequency dependence of the relationship between FW content and circulation changes by running a cross-spectral analysis of the aforementioned indices: namely, FW content changes, the subpolar gyre strength (monitored in the Labrador and Irminger Seas, respectively), and the AMOC. To address our objective, which is to clarify whether the subpolar gyre is fresher or saltier when circulation is more intense, we focus on the phase of the cross-spectra. Most particularly, we look for frequencies when the phase is either 0 or $2 \pi$, suggesting that the subpolar gyre is fresher when the circulation is more intense (configuration $A)$ and when the phase is $\pi(\bmod 2 \pi)$, suggesting that the subpolar gyre is saltier when the circulation is more intense (configuration B). All other values of the phase indicate a transitionary situation that is not straightforward to interpret. We incorporate two levels of significance in those estimates. First, we only consider phase estimates at frequencies when the coherence is significant (at 95\% confidence level, following Amos and Koopmans 1963). Second, we calculate the uncertainty of the phase estimate (at 95\% confidence level) using a Monte Carlo procedure with 50 iterations.

In the GFDL model, FW content changes and AMOC are out of phase at all frequencies: that is, the subpolar gyre is saltier when the AMOC is more intense (Fig. 7a, orange markers). The phase shift between FW content changes and the subpolar gyre strength varies from $0 \pm 2 \pi$ at interannual frequencies to $\pi$ at multidecadal frequencies. Hence, at interannual frequencies, the subpolar 


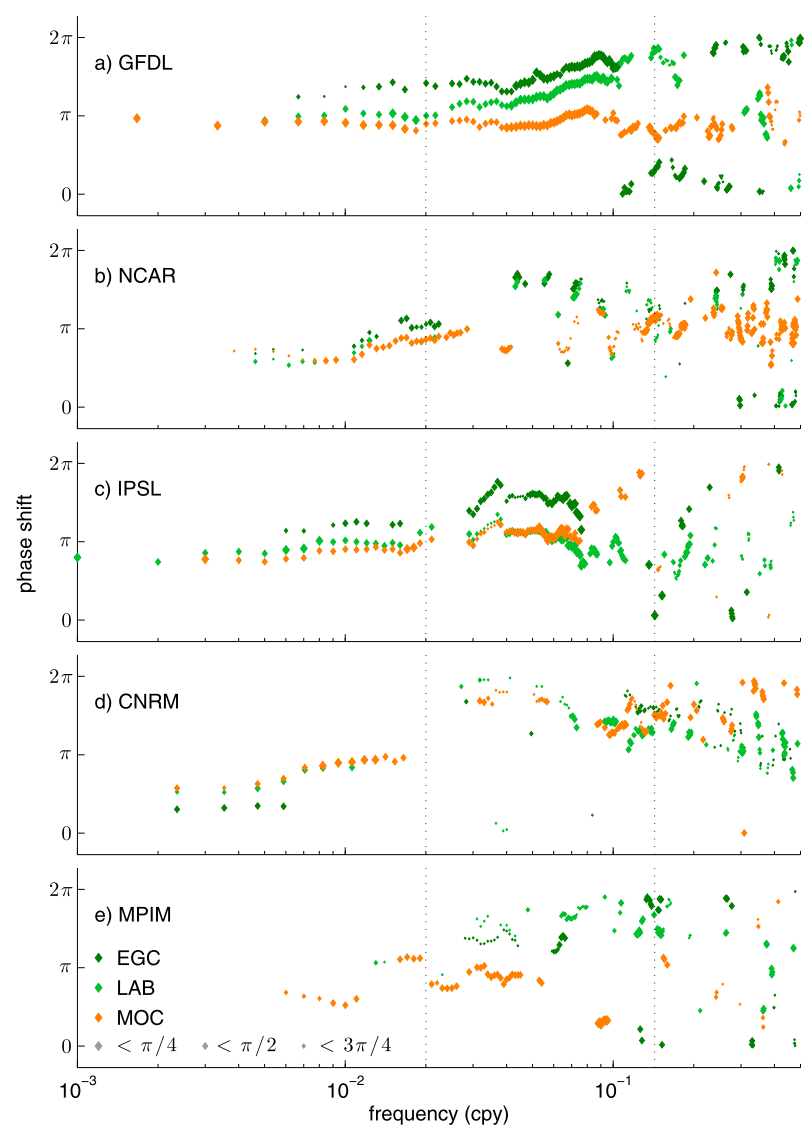

FIG. 7. Phase of the cross-spectra between freshwater content changes and AMOC (orange markers), subpolar gyre strength in the Irminger Sea (dark green markers), and subpolar gyre strength in the Labrador Sea (light green markers) in CMIP5 climate models. The size of the marker is inversely proportional to the $95 \%$ uncertainty level of the phase estimate [see legend in (e); the larger the marker, the smaller the uncertainty]. Phase estimates are only given at frequencies where the coherence is larger than the $95 \%$ confidence level. Dotted lines indicate cutoff periods used in Fig. 6.

gyre is fresher when it is more intense, while at multidecadal frequencies the subpolar gyre is saltier when it is more intense. This is a direct verification of our working hypothesis, although it is only visible here for the subpolar gyre strength and not for the AMOC.

Phase shifts are similar in the NCAR model, although there are fewer frequencies when the coherence is significant (in particular at decadal periods) and the uncertainty in phase estimate is larger (Fig. 7b). Still, it is obvious that FW content changes vary out of phase with the AMOC at interannual to multidecadal frequencies: that is, the subpolar gyre is saltier when the AMOC is more intense. The phase shift between FW content and the subpolar gyre strength varies from close to $0 \pm 2 \pi$ at interannual frequencies to $\pi$ at multidecadal frequencies, but this is not as visible as in GFDL.
TABLE 4. Summary of cross-spectral analysis between FW content in the subpolar gyre and circulation indices. Only significant and robust tendencies are indicated.

When the AMOC is intense, the subpolar gyre is

\begin{tabular}{llcc}
\hline & HF & DF & LF \\
\hline GFDL & saltier & saltier & saltier \\
NCAR & saltier & - & saltier \\
IPSL & fresher & saltier & saltier \\
CNRM & - & - & saltier \\
MPI-M & - & saltier & - \\
When the subpolar & gyre is intense, it is & &
\end{tabular}

\begin{tabular}{lccc}
\hline & HF & DF & LF \\
\hline GFDL & fresher & - & saltier \\
NCAR & fresher & - & - \\
IPSL & saltier & saltier & saltier \\
CNRM & - & - & - \\
MPI-M & - & - & - \\
\hline
\end{tabular}

In the IPSL model, FW content changes and circulation indices behave in a similar fashion as in GFDL for periods longer than $12 \mathrm{yr}$ (Fig. 7c). At higher frequency, $\mathrm{FW}$ content changes and AMOC vary in phase (although the coherence is significant for a few frequencies only): that is, the subpolar gyre is fresher when the AMOC is more intense. FW content changes and subpolar gyre strength, when monitored in the Labrador Sea, vary out of phase: the subpolar gyre is saltier when it is more intense. Hence, in this model our working hypothesis is verified but only for the AMOC.

The picture that emerges from the CNRM and MPI-M models is more complex to interpret for several reasons: (i) coherence is significant for selected frequencies only, (ii) the uncertainty in phase estimate is large, and (iii) phase estimates do not cluster around $0 \pm 2 \pi$ or $\pi$ (Figs. 7d,e). Still, in the CNRM model at multidecadal frequencies and in the MPI-M model for periods between 15 and $70 \mathrm{yr}, \mathrm{FW}$ content and the AMOC tend to vary out of phase, i.e., the subpolar gyre is saltier when the AMOC is more intense.

These results are summarized in Table 4, where we only reported the largest and most reliable tendencies for each frequency band used in lag correlations. Our working hypothesis-that the subpolar gyre is fresher when circulation is more intense (configuration $\mathrm{A}$ ) at high frequency but saltier (configuration B) at low frequency is verified in GFDL for the subpolar gyre and in IPSL for the AMOC. The other two models are inconclusive with regard to this hypothesis. Hence, we conclude that the relationship between the AMOC, the subpolar gyre strength, and FW content in the subpolar gyre is, overall, model dependent. 


\section{Discussion}

A principal result of this paper is a broadly inconsistent representation of FW budgets and circulation in the subpolar North Atlantic in CMIP5 climate models. Incidentally, we note that the IPSL and CNRM models share the same general ocean circulation model, $\mathrm{Nu}$ cleus for European Modelling of the Ocean (NEMO), and still differ largely in FW budget and circulation strength. Because the subpolar gyre plays a fundamental role in the oceanic contribution to climate (e.g., Yeager et al. 2012; Robson et al. 2012; Msadek et al. 2013, manuscript submitted to J. Climate), it is essential that more studies address these differences between models, assert their impact on future climate variability, and identify improvements necessary to obtain a convergence among their representations of FW budgets. Our model intercomparison study is a first step in this direction. In the following, we discuss two weaknesses of climate models that may have affected their subpolar FW budget.

Variability of the hydrography and circulation in the North Atlantic on interannual to decadal time scales is predominantly induced by atmospheric variability (via wind and buoyancy forcing), although oceanic mesoscale processes also generate internal variability on those time scales (Deshayes et al. 2009; Penduff et al. 2011). Atmospheric variability can be described as reversals from positive to negative phases of the NAO, combined with other modes of variability or weather regimes (Cassou et al. 2011). Atmospheric fluctuations control both local surface fluxes of freshwater (through $P-E+R$ ) and FW convergence (via changes in circulation or remote surface fluxes). The atmospheric components of coupled climate models show recurrent biases, such as the representation of NAO fluctuations, that remain in the CMIP5 models investigated here (for GFDL, see Gent et al. 2011; for CNRM, see Voldoire et al. 2012). These biases may affect the FW budget and its relationship with the circulation in the subpolar North Atlantic. In view of the dependence of our results on the model used, it is likely that this is happening. Hence, this study encourages further investigation of what factors control FW variability and circulation changes in each of these models and whether these are correctly represented.

In all simulations, correlations between circulation indices and subpolar FW content show that intensified gyre and overturning circulations are associated with a decrease in FW content due to increased northward salt transport at the southern boundary of the subpolar gyre (at interannual and/or decadal frequencies, depending on the simulation). Because these anomalies occur in phase or with a few years lag, we speculate that it is due to anomalies in the circulation of FW in the North Atlantic midlatitudes (rather than, e.g., the advection of tropical salinity anomalies that would require a longer time lag). This region-where section $42 \mathrm{~N}$ is located (see Fig. 2; viz., the intergyre gyre) - is a cornerstone for atmospheric driving of oceanic variability: wind stress curl fluctuations drive large-scale gyre anomalies that influence exchanges between the subtropical and subpolar gyres (Marshall et al. 2001; Hakkinen et al. 2011). The assumption that the subpolar gyre and AMOC exert a direct influence on FW transport across the intergyre gyre is an original outcome of our study that calls for specific investigations to assess its validity. Indeed, in low-resolution ocean models the upper-ocean temperature and salinity in this region show persistent flaws due to biases in the Gulf Stream and North Atlantic Current pathways (Griffies et al. 2009). Circulation of dense water masses from the Nordic Seas that is commonly misrepresented in climate models, except when a specific parameterization is implemented such as in NCAR, is likely to influence the upper-ocean hydrography in this region as well. Finally, atmospheric biases in climate models may affect intergyre gyre dynamics and exchanges of freshwater between the subtropical and subpolar gyres.

A recent study of Escudier et al. (2013) investigates the decadal cycle in the very same simulation of the IPSL model. They observe that near-surface salinity anomalies, which are formed and propagate within the subpolar gyre, play an active role in the subpolar gyre and AMOC decadal variability, positive salinity anomalies inducing convection, and hence intensification of both circulations. This mechanism is not visible in our results, where intensification of the AMOC and subpolar gyre lags by about $10 \mathrm{yr}$ an increase in subpolar gyre FW content. These conclusions may seem contradictory, but it should be kept in mind that we integrate FW content changes over the whole subpolar gyre, from the surface to the bottom, while Escudier et al. (2013) consider only surface salinity anomalies in the sole regions of convection. Hence, our results cannot be directly compared to those of Escudier et al. (2013).

\section{Conclusions}

In this paper, we investigate the relationships between FW content and circulation in the North Atlanticnamely, the subpolar gyre strength and the AMOCbecause they constrain the oceanic contribution to climate variability. To explain the inconsistency between recent observations, hindcast simulations and climate models, we reconstruct FW budget in five CMIP5 climate models (called GFDL, NCAR, CNRM, IPSL, and MPI-M by their institutes). In particular, we look for 
evidences of two configurations: a fresher subpolar gyre as circulation is more intense, as suggested by observations and hindcast simulations (configuration $\mathrm{A}$ ), and a saltier subpolar gyre as circulation is more intense, as shows up most often in climate models (configuration B). Our working hypothesis is that configuration A preferentially occurs at high frequency, while configuration B dominates at longer periods. When we consider the five simulations altogether, our hypothesis is verified, but our results mostly highlight the large differences in FW budget among the models.

We introduce a novel intercomparison methodology, PAGO, to diagnose FW budget (essentially FW content and convergence through lateral boundaries) in a physically consistent framework. This methodology identifies physical sections within model grids and calculates transport normal to these sections with minimum interpolation of the coordinates and velocities. We claim that this method is robust for intercomparison of models because we calculate the exact same physical quantities in each model simulation. This method also allows us to synthesize variability of full-depth North Atlantic hydrography and circulation into few time series. The PAGO strategy is likely to be even more relevant when analyzing ocean and climate models at increasing spatial resolution.

Mean and standard deviation of all terms in the FW budget are very different among models (they vary by more than a factor 2). FW convergence through lateral boundaries mostly reflects the transport at the southern boundary of the subpolar gyre, for both the mean and the variability, which suggests that subtropical influence on subpolar FW budget overcomes that of polar regions. In GFDL, IPSL, and CNRM, its fluctuations have comparable variance and are highly correlated with FW content changes, whereas surface fluxes and diffusion have a much smaller impact. In NCAR and MPI-M, surface fluxes gain importance in the FW budget. The high correlation between FW content changes and FW convergence is consistent with hindcast simulations (e.g., Frankignoul et al. 2009) and the preindustrial control run of another climate model (Wu and Wood 2008). Direct observations of oceanic full-depth circulation are too rare to evaluate FW convergence to the subpolar gyre and check whether this result is realistic. One preliminary step would be to compare the range of variability of FW content in these models with estimates from a compilation of available observations in the subpolar gyre, but the latter must come with an estimate of the error because of the interpolation in space and time of sparse observations.

Relationships between FW content changes and the subpolar gyre strength and the AMOC are investigated using lag correlations and phase estimate of the crossspectra. When considering the five models together, configuration A is only visible at interannual frequency, while configuration $\mathrm{B}$ dominates at decadal and multidecadal frequency, which confirms our working hypothesis. In the GFDL model, the subpolar gyre intensifies as FW content increases, on an interannual time scale, while FW content decreases as the subpolar gyre intensifies on a multidecadal time scale. In IPSL, FW content increases as the AMOC is more intense, on an interannual time scale, while $\mathrm{FW}$ content decreases as AMOC is more intense on decadal and multidecadal time scales. These two elements are direct confirmations of our working hypothesis. Nevertheless, the other models show inconclusive results that do not allow us to either confirm or contradict our hypothesis. For this reason, we advocate that more intercomparative studies in a physical framework be carried out as we did with PAGO, in order for a better understanding of the role of North Atlantic subpolar FW anomalies in climate variability to be gained.

Acknowledgments. We are thankful to the modeling groups that gave us access to their control simulations before they were available to public, in particular to Juliette Mignot, Laurent Terray, Aurore Voldoire, David Salas, Gokhan Danabasoglu, and Claude Talandier. Discussions with Juliette Mignot and Didier Swingedouw are sincerely acknowledged. We also acknowledge the editor, Anand Gnanadesikan, as well as the three anonymous reviewers, for their helpful comments. Multitaper single and cross-spectral analyses were performed using P. Huybers functions (http://www.people.fas.harvard. edu/ phuybers/Mfiles/). JD and RC were funded by NSF through Project 0751896. JD was also funded by IFREMER through project RICCO.

\section{REFERENCES}

Amos, D. E., and L. H. Koopmans, 1963: Tables of the Distribution of the Coefficient of Coherence for Stationary Bivariate Gaussian Processes. Sandia Corporation Monogr., No. SCR-483, Sandia, 365 pp.

Bond, G., and Coauthors, 1992: Evidence for massive discharges of icebergs into the North Atlantic Ocean during the last glacial period. Nature, 360, 245-249, doi:10.1038/360245a0.

Boyle, E. Q., and L. D. Keigwin, 1982: Deep circulation of the North Atlantic over the last 200,000 years: Geochemical evidence. Science, 218, 784-787, doi:10.1126/science.218.4574.784.

Bretherton, C. S., M. Widmann, V. P. Dymnikov, J. M. Wallace, and I. Blad, 1999: The effective number of spatial degrees of freedom of a time-varying field. J. Climate, 12, 1990-2009, doi:10.1175/1520-0442(1999)012<1990:TENOSD>2.0.CO;2.

Broecker, W. S., 1994: Massive iceberg discharges as triggers for global climate change. Nature, 372, 421-424, doi:10.1038/372421a0.

Cassou, C., M. Minvielle, L. Terray, and C. Prigaud, 2011: A statisticaldynamical scheme for reconstructing ocean forcing in the 
Atlantic. Part I: Weather regimes as predictors for ocean surface variables. Climate Dyn., 36, 19-39, doi:10.1007/ s00382-010-0781-7.

Charles, C. D., and R. G. Fairbanks, 1992: Evidence from Southern Ocean sediments for the effect of North Atlantic deep-water flux on climate. Nature, 355, 416-419, doi:10.1038/355416a0.

Clarke, R. A., 1984: Transport through the Cape Farewell-Flemish Cap section. Rapp. P.-V. Reun., 185, 120-130.

Cunningham, S. A., and Coauthors, 2007: Temporal variability of the Atlantic meridional overturning circulation at $26.5^{\circ} \mathrm{N}$. Science, 317, 935-938, doi:10.1126/science.1141304.

Cuny, J., P. B. Rhines, and R. Kwok, 2005: Davis Strait volume, freshwater and heat fluxes. Deep-Sea Res., 52, 519-542, doi:10.1016/j.dsr.2004.10.006.

Curry, R. G., and M. S. McCartney, 2001: Ocean Gyre circulation changes associated with the North Atlantic Oscillation. J. Phys. Oceanogr., 31, 3374-3400, doi:10.1175/1520-0485(2001)031<3374: OGCCAW $>2.0 . \mathrm{CO} ; 2$.

- and C. Mauritzen, 2005: Dilution of the northern North Atlantic Ocean in recent decades. Science, 308, 1772-1774, doi:10.1126/science.1109477.

— B. D. Dickson, and I. Y. Yashayaev, 2003: A change in the freshwater balance of the Atlantic Ocean over the past four decades. Nature, 426, 826-829, doi:10.1038/nature02206.

Danabasoglu, G., W. G. Large, and B. P. Briegleb, 2010: Climate impacts of parameterized Nordic Sea overflows. J. Geophys. Res., 115, C11005, doi:10.1029/2010JC006243.

—_ S. C. Bates, B. P. Briegleb, S. R. Jayne, M. Jochum, W. G. Large, S. Peacock, and S. G. Yeager, 2012: The CCSM4 ocean component. J. Climate, 25, 1361-1389, doi:10.1175/ JCLI-D-11-00091.1.

Delworth, T., and Coauthors, 2012: Simulated climate and climate change in the GFDL CM2.5 high-resolution coupled climate model. J. Climate, 25, 2755-2781, doi:10.1175/JCLI-D-11-00316.1.

Deshayes, J., and C. Frankignoul, 2008: Simulated variability of the circulation in the North Atlantic from 1953 to 2003. J. Climate, 21, 4919-4933, doi:10.1175/2008JCLI1882.1.

_- F. Straneo, and M. Spall, 2009: Mechanisms of variability in a convective basin. J. Mar. Res., 67, 273-303, doi:10.1357/ 002224009789954757.

Dickson, R. R., J. Meincke, S. A. Malmberg, and A. J. Lee, 1988: The "Great Salinity Anomaly" in the northern North Atlantic 1968-1982. Prog. Oceanogr., 20,103-151, doi:10.1016/ 0079-6611(88)90049-3.

_ I. Yashayaev, J. Meincke, B. Turrell, S. Dye, and J. Holfort, 2002: Rapid freshening of the deep North Atlantic Ocean over the past four decades. Nature, 416, 832-837, doi:10.1038/416832a.

Donner, L. J., and Coauthors, 2011: The dynamical core, physical parameterizations, and basic simulation characteristics of the atmospheric component AM3 of the GFDL global coupled model CM3. J. Climate, 24, 3484-3519, doi:10.1175/ 2011JCLI3955.1.

Dufresne, J. L., and Coauthors, 2013: Climate change projections using the IPSL-CM5 Earth system model: From CMIP3 to CMIP5. Climate Dyn., 40, 2123-2165, doi:10.1007/ s00382-012-1636-1.

Escudier, R., J. Mignot, and D. Swingedouw, 2013: A 20-year coupled ocean-sea ice-atmosphere variability mode in the North Atlantic in an AOGCM. Climate Dyn., 40, 619-636, doi:10.1007/s00382-012-1402-4.

Frankcombe, M., and A. Dijkstra, 2011: The role of Atlantic-Arctic exchange in North Atlantic multidecadal climate variability. Geophys. Res. Lett., 38, L16603, doi:10.1029/2011GL048158.
Frankignoul, C., J. Deshayes, and R. Curry, 2009: The role of salinity in the decadal variability of the North Atlantic meridional overturning circulation. Climate Dyn., 33, 777-793, doi:10.1007/ s00382-008-0523-2.

Gent, P. R., and J. C. McWilliams, 1990: Isopycnal mixing in ocean circulation models. J. Phys. Oceanogr., 20, 150-155, doi:10.1175/ 1520-0485(1990)020<0150:IMIOCM > 2.0.CO;2.

_ , and Coauthors, 2011: The Community Climate System Model version 4. J. Climate, 24, 4973-4991, doi:10.1175/2011JCLI4083.1.

Griffies, S. M., and Coauthors, 2009: Coordinate Ocean-ice Reference Experiments (COREs). Ocean Modell., 26, 1-46, doi:10.1016/j.ocemod.2008.08.007.

_ , and Coauthors, 2011: The GFDL CM3 coupled climate model: Characteristics of the ocean and sea ice simulations. J. Climate, 24, 3520-3544, doi:10.1175/2011JCLI3964.1.

Guemas, V., and F. Codron, 2011: Differing impacts of resolution changes in latitude and longitude on the midlatitudes in the LMDZ atmospheric GCM. J. Climate, 24, 5831-5849, doi:10.1175/2011JCLI4093.1.

Haak, H., J. Jungclaus, U. Mikolajewicz, and M. Latif, 2003: Formation and propagation of great salinity anomalies. Geophys. Res. Lett., 30, 1473, doi:10.1029/2003GL017065.

Hakkinen, S., and P. B. Rhines, 2004: Decline of subpolar North Atlantic circulation during the 1990s. Science, 304, 555-559, doi:10.1126/science.1094917.

— — - a and D. L. Worthen, 2011: Atmospheric blocking and Atlantic multidecadal ocean variability. Science, 334, 655-659, doi:10.1126/science.1205683.

Hall, M. M., D. J. Torres, and I. Yashayaev, 2013: Absolute velocity along the AR7W section in the Labrador Sea. Deep-Sea Res. I, 72, 72-87, doi:10.1016/j.dsr.2012.11.005.

Hallberg, R., and P. B. Rhines, 1996: Buoyancy-driven circulation in an ocean basin with isopycnals intersecting the sloping boundary. J. Phys. Oceanogr., 26, 913-940, doi:10.1175/ 1520-0485(1996)026<0913:BDCIAO > 2.0.CO;2.

Hátún, H., A. B. Sand $\varnothing$, H. Drange, B. Hansen, and H. Valdimarsson, 2005: Influence of the Atlantic subpolar gyre on the thermohaline circulation. Science, 309, 1841-1844, doi:10.1126/science.1114777.

Herbaut, C., and M.-N. Houssais, 2009: Response of the eastern North Atlantic subpolar gyre to the North Atlantic Oscillation. Geophys. Res. Lett., 36, L17607, doi:10.1029/2009GL039090.

Hsieh, W. W., M. K. Davey, and R. C. Wajsowicz, 1983: The free Kelvin wave in finite-difference numerical models. J. Phys. Oceanogr., 13, 1383-1397, doi:10.1175/1520-0485(1983)013<1383: TFKWIF $>2.0 . \mathrm{CO} ; 2$.

Jungclaus, J. H., H. Haak, M. Latif, and U. Mikolajewicz, 2005: Arctic-North Atlantic interactions and multidecadal variability of the meridional overturning circulation. J. Climate, 18, 4013-4031, doi:10.1175/JCLI3462.1.

— , N. Fischer, H. Haak, K. Lohmann, J. Marotzke, D. Matei, U. Mikolajewicz, D. Notz, and S. von Storch, 2013: Characteristics of the ocean simulations in the Max Planck Institute Ocean Model (MPIOM) the ocean component of the MPIEarth system model. J. Adv. Model. Earth Syst., 5, 422-446, doi:10.1002/jame.20023.

Kuhlbrodt, T., A. Griesel, M. Montoya, A. Levermann, M. Hofmann, and S. Rahmstorf, 2007: On the driving processes of the Atlantic meridional overturning circulation. Rev. Geophys., 45, RG2001, doi:10.1029/2004RG000166.

Latif, M., E. Roeckner, U. Mikolajewicz, and R. Voss, 2000: Tropical stabilization of the thermohaline circulation in a greenhouse warming simulation. J. Climate, 13, 1809-1813, doi:10.1175/1520-0442(2000)013<1809:L>2.0.CO;2. 
_ C. W. Boning, J. Willebrand, A. Biastoch, J. Dengg, N. Keenlyside, U. Schweckendiek, and G. Madec, 2006: Is the thermohaline circulation changing? J. Climate, 19, 4631-4637, doi:10.1175/JCLI3876.1.

Marshall, J., H. Johnson, and J. Goodman, 2001: A study of the interaction of the North Atlantic Oscillation with ocean circulation. J. Climate, 14, 1399-1421, doi:10.1175/1520-0442(2001)014<1399: ASOTIO $>2.0 . \mathrm{CO} ; 2$.

Mauritzen, C., S. S. Hjollo, and A. B. Sando, 2006: Passive tracers and active dynamics: A model study of hydrography and circulation in the northern North Atlantic. J. Geophys. Res., 111, C08014, doi:10.1029/2005JC003252.

Meehl, G. A., and Coauthors, 2007: Global climate projections. Climate Change 2007: The Physical Science Basis, S. Solomon et al., Eds., Cambridge University Press, 747-846.

Mignot, J., and C. Frankignoul, 2005: On the variability of the Atlantic meridional overturning circulation, the North Atlantic Oscillation, and the El Niño-Southern Oscillation in the Bergen Climate Model. J. Climate, 18, 2361-2375, doi:10.1175/ JCLI3405.1.

Penduff, T., M. Juza, B. Barnier, J. Zika, W. K. Dewar, A.-M. Treguier, J.-M. Molines, and N. Audiffren, 2011: Sea level expression of intrinsic and forced ocean variabilities at interannual time scales. J. Climate, 24, 5652-5670, doi:10.1175/ JCLI-D-11-00077.1.

Peterson, B. J., J. McClelland, R. Curry, R. M. Homes, J. E. Walsh, and K. Aagaard, 2006: Trajectory shifts in the Arctic and subarctic freshwater cycle. Science, 313, 1061-1065, doi:10.1126/ science.1122593.

Pickart, R. S., and M. A. Spall, 2007: Impact of Labrador Sea convection on the North Atlantic meridional overturning circulation. J. Phys. Oceanogr., 37, 2207-2227, doi:10.1175/ JPO3178.1.

Rahmstorf, S., 2002: Ocean circulation and climate during the past 120,000 years. Nature, 419, 207-214, doi:10.1038/nature01090.

Rayner, D., and Coauthors, 2011: Monitoring the Atlantic meridional overturning circulation. Deep-Sea Res. II, 58, 1744-1753, doi:10.1016/j.dsr2.2010.10.056.

Reynaud, T. H., A. J. Weaver, and R. J. Greatbatch, 1995: Summer mean circulation of the northwestern Atlantic Ocean. J. Geophys. Res., 100, 779-816, doi:10.1029/94JC02561.

Robson, J. I., R. Sutton, and D. M. Smith, 2012: Initialized decadal predictions of the rapid warming of the North Atlantic Ocean in the mid 1990s. Geophys. Res. Lett., 39, L19713, doi:10.1029/ 2012GL053370.

Stouffer, R. J., and Coauthors, 2006: Investigating the causes of the response of the thermohaline circulation to past and future climate changes. J. Climate, 19, 1365-1387, doi:10.1175/ JCLI3689.1.

Swingedouw, D., P. Braconnot, P. Delecluse, E. Guilyardi, and O. Marti, 2007: The impact of global freshwater forcing on the thermohaline circulation: Adjustment of North Atlantic convection sites in a CGCM. Climate Dyn., 28, 291-305, doi:10.1007/s00382-006-0171-3.

Talley, L. D., 2008: Freshwater transport estimates and the global overturning circulation: Shallow, deep and throughflow components. Prog. Oceanogr., 78, 257-303, doi:10.1016/ j.pocean.2008.05.001.

Taylor, K. E., R. J. Stouffer, and G. A. Meehl, 2009: A summary of the CMIP5 experiment design. PCMDI Rep., 33 pp. [Available online at http://cmip-pcmdi.llnl.gov/cmip5/docs/ Taylor_CMIP5_design.pdf.]

Timmermann, A., M. Latif, R. Voss, and A. Grötzner, 1998: Northern Hemispheric interdecadal variability: A coupled air-sea mode. J. Climate, 11, 1906-1931, doi:10.1175/ 1520-0442-11.8.1906.

Treguier, A. M., I. M. Held, and V. D. Larichev, 1997: Parameterization of quasigeostrophic eddies in primitive equation ocean models. J. Phys. Oceanogr., 27, 567-580, doi:10.1175/ 1520-0485(1997)027<0567:POQEIP > 2.0.CO;2.

J. Deshayes, C. Lique, R. Dussin, and M. Molines, 2012: Eddy contributions to the meridional transport of salt in the North Atlantic. J. Geophys. Res., 117, C05010, doi:10.1029/ 2012JC007927.

Vellinga, M., and P. Wu, 2004: Low-latitude freshwater influence on centennial variability of the Atlantic thermohaline circulation. J. Climate, 17, 4498-4511, doi:10.1175/3219.1.

Vidal, L., L. Labeyrie, E. Cortijo, M. Arnold, J. C. Duplessy, E. Michel, S. Becque, and T. C. E. van Weering, 1997: Evidence for changes in the North Atlantic Deep Water linked to meltwater surges during the Heinrich events. Earth Planet. Sci. Lett., 146, 13-27, doi:10.1016/S0012-821X(96)00192-6.

Voldoire, A., and Coauthors, 2012: The CNRM-CM5.1 global climate model: Description and basic evaluation. Climate Dyn., 40, 2091-2121, doi:10.1007/s00382-011-1259-y.

Weaver, A. J., and Coauthors, 2012: Stability of the Atlantic meridional overturning circulation: A model intercomparison. Geophys. Res. Lett., 39, L20709, doi:10.1029/2012GL053763.

Wu, P., and R. Wood, 2008: Convection induced long term freshening of the subpolar North Atlantic Ocean. Climate Dyn., 31, 941-956, doi:10.1007/s00382-008-0370-1.

Wunsch, C., and P. Heimbach, 2009: The global zonally integrated ocean circulation, 1992-2006: Seasonal and decadal variability. J. Phys. Oceanogr., 39, 351-368, doi:10.1175/2008JPO4012.1.

Yashayaev, I., 2007: Hydrographic changes in the Labrador Sea, 1960-2005. Prog. Oceanogr., 73, 242-276, doi:10.1016/ j.pocean.2007.04.015.

Yeager, S. G., A. Karspeck, G. Danabasoglu, J. Tribia, and H. Teng, 2012: A decadal prediction case study: Late twentieth-century North Atlantic Ocean heat content. J. Climate, 25, 5173-5189, doi:10.1175/JCLI-D-11-00595.1.

Zhang, R., and T. L. Delworth, 2006: Impact of Atlantic multidecadal oscillations on India/Sahel rainfall and Atlantic hurricanes. Geophys. Res. Lett., 33, L17712, doi:10.1029/2006GL026267. 